\title{
Phase Inversion Tape Casting and Oxygen Permeation Properties of Supported
}

\author{
Planar $\mathrm{Zr}_{0.84} \mathrm{Y}_{0.16} \mathrm{O}_{1.92}-\mathrm{La}_{0.8} \mathrm{Sr}_{0.2} \mathrm{Cr}_{0.5} \mathrm{Fe}_{0.5} \mathrm{O}_{3-\delta}$ Composite Membrane
}

Yu Zhang, Rong-hua Yuan, Zhen-yu He, Jian-feng Gao*, Chu-sheng Chen*

CAS Key Laboratory of Materials for Energy Conversion, Collaborative Innovation Center of Chemistry for Energy Materials, and Department of Materials Science and Engineering, University of Science and Technology of China, Hefei 230026, China

*Correspondence and requests for materials should be addressed to J.F. Gao (E-mail: jfgao@ustc.edu.cn) and C.S. Chen (E-mail: ccsm@ustc.edu.cn)

\section{Abstract}

The $\mathrm{Zr}_{0.84} \mathrm{Y}_{0.16} \mathrm{O}_{1.92}$ (YSZ)- $\mathrm{La}_{0.8} \mathrm{Sr}_{0.2} \mathrm{Cr}_{0.5} \mathrm{Fe}_{0.5} \mathrm{O}_{3-\delta}$ (LSCrF) composite membrane was prepared using the phase inversion tape casting method. Two slurries, one composed of YSZ and LSCrF powder, and the other composed also graphite, were used for preparation of the membrane. They were co-tape cast onto a Mylar sheet, and then immersed in a water bath for solidification into a green tape through phase inversion mechanism. After sintering at $1450{ }^{\circ} \mathrm{C}$ in the air, the green tape was converted into a ceramic membrane. The sintered membrane possessed an asymmetric structure: a dense layer of thickness $\sim 30 \mu \mathrm{m}$ and a finger-like porous support of thickness $\sim 1 \mathrm{~mm}$. The membrane was further modified by applying a porous YSZ-LSCrF layer on its surfaces at the dense layer side and depositing $\mathrm{Sm}_{0.2} \mathrm{Ce}_{0.8} \mathrm{O}_{2}$ nano-particles on the inner surfaces of the support. The oxygen permeability of the as-prepared membrane was measured by exposing its dense layer side to air and the support side to $\mathrm{CO}$ at elevated temperatures. The membrane exhibited desired oxygen permeability under the given measurement conditions. An oxygen 
permeation flux as large as $2.4 \mathrm{ml} \cdot \mathrm{cm}^{-2} \cdot \mathrm{min}^{-1}$ (STP) was observed at $900{ }^{\circ} \mathrm{C}$, which is comparable to the hollow fiber membrane of the same composition. Owing to its desired oxygen permeability and good stability, the supported planar YSZ-LSCrF membrane developed in the present study holds promise for applications in chemical reactors integrating oxygen separation and oxygen-consuming chemical reactions such as partial oxidation of methane (POM). The phase inversion tape casting method explored in the present study can be applied to the preparation of other ceramic membranes.

Key words: tape casting; phase inversion; composite membrane; oxygen permeation

\section{Introduction}

Dense membranes made of ceramic materials that can conduct both oxide ions and electrons allow oxygen to permeate in the presence of oxygen partial pressure gradient [1]. These membranes hold promise to bring about a step-change to the production of oxygen from air and oxygen-consuming industrial chemical process $[2,3]$. For example, a membrane-based reactor integrating oxygen separation and partial oxidation of methane (POM) into a single space is expected to significantly reduce the production cost of syngas $[4,5]$, an intermediate for production of liquid fuels, hydrogen and other value-added chemicals. For successful applications, the membrane is required to possess a high oxygen permeation flux, higher than $1 \mathrm{ml} \cdot \mathrm{cm}^{-2} \cdot \mathrm{min}^{-1}$ (STP) [6] and chemical and mechanical stabilities under stringent operation conditions.

Most of membrane materials explored so far are oxygen-deficient perovskite-structured oxides such as $(\mathrm{Ln}, \mathrm{A})(\mathrm{Co}, \mathrm{B}) \mathrm{O}_{3-\delta}(\mathrm{Ln}=$ rare earth elements, $\mathrm{A}=\mathrm{Ca}, \mathrm{Sr}, \mathrm{Ba}, \mathrm{B}=$ transition metal 
elements) $[7,8]$. These membranes exhibit high oxygen permeation fluxes as required for practical applications, but their stabilities especially under the POM reactor conditions are questionable.[9, 10] The other type of membrane materials explored is the dual-phase composite in which oxide ions and electrons are transported through different phases. In comparison with the single-phase material, composites with right choice of constituent phases exhibit better stabilities. For example, the composite membrane, comprising $\mathrm{Zr}_{0.84} \mathrm{Y}_{0.16} \mathrm{O}_{1.92}$ (YSZ) as oxygen ionic conductor and $\mathrm{La}_{0.8} \mathrm{Sr}_{0.2} \mathrm{Cr}_{0.5} \mathrm{Fe}_{0.5} \mathrm{O}_{3-\delta}$ (LSCrF) [11] as electronic conductor, can remain intact under a large oxygen gradient (air/CO) [12]. The drawback of dual-phase composite membranes is their low oxygen permeability relative to the single-phase materials. However, this drawback can be overcome by fabricating the composite membranes into an asymmetric structure in which a thin dense oxygen-permeable layer is mechanically supported by a thick porous layer.

There are a variety of methods for preparation of supported membranes [13]. Those methods usually start with the preparation of a porous support followed by applying a separation layer on it [14]. The porous support is prepared by standard ceramic processing methods using fugitive pore formers such as graphite or starch which are present in the green body and removed in the subsequent firing step. The dense layer then is applied on the as-prepared support using methods such as slip casting [15], dip-coating [16], chemical vapor deposition [17] or screen printing [18]. Recently, tape casting involving phase inversion has been explored for preparation of supported planar ceramic membranes [19-21].This method has an advantage of allowing simultaneous preparation of the dense separation layer and the porous mechanical support. In this method, a slurry of ceramic powders dispersed in an organic polymer solution is tape cast onto a substrate, and immersed in a water bath for solidification into a green tape via the phase inversion 
mechanism. The as-formed green tape comprises a sponge-like bottom layer and a thick finger-like porous layer. After firing at elevated temperatures, the green tape is sintered into a ceramic membrane: the sponge like layer of the green tape is converted into a dense separation layer while the finger-like layer is converted into a porous support.

In the present study, a new variant of the phase inversion tape casting method was explored for preparation of supported planar membrane. Unlike the previously reported method which makes use of a single slurry $[19,20]$, the new method makes use of two different slurries, one for preparation of the dense separation layer of the membrane, and the other for preparation of the support. Consequently, the thickness of the dense separation layer and the porosity of the support can be optimized independently. With this newly developed method, planar supported YSZ-LSCrF membranes were prepared, and their oxygen permeability was examined in relation to the membrane structure and surface modification.

\section{Experiment}

\subsection{Membrane preparation}

Two slurries with composition listed in Table 1 were prepared using the method described in Ref. [19]. The $\mathrm{Zr}_{0.84} \mathrm{Y}_{0.16} \mathrm{O}_{1.92}$ (YSZ) powder used was supplied by Fanmeiya with purity $>99 \%$ and the $\mathrm{La}_{0.8} \mathrm{Sr}_{0.2} \mathrm{Cr}_{0.5} \mathrm{Fe}_{0.5} \mathrm{O}_{3-\delta}$ ( $\mathrm{LSCrF}$ ) powder was home-made using the solid state reaction method described in Ref. [12]. The two slurries were co-tape cast onto a Mylar sheet using the device illustrated in Fig. 1 with the blade gaps of $0.06 \mathrm{~mm}$ and $1.30 \mathrm{~mm}$ for slurry 1 and slurry 2 , respectively, and then immersed in a water bath for solidification into a green tape via the phase inversion mechanism. The as-formed green tape was cut into a required size $\left(6 \times 6 \mathrm{~cm}^{2}\right.$ in this 
study), and sintered at $1450{ }^{\circ} \mathrm{C}$ for $10 \mathrm{~h}$.

Table 1 Composition of slurries for phase-inversion tape casting (wt \%)

\begin{tabular}{ccc}
\hline & Slurry 1 & Slurry 2 \\
Composition & (graphite-free layer) & (graphite-containing layer) \\
\hline NMP & 20.2 & 31.4 \\
PESf & 3.4 & 5.2 \\
PVP & 0.6 & 1.3 \\
YSZ & 43.7 & 28.6 \\
LSCrF & 32.1 & 21.0 \\
Graphite & 0 & 12.5 \\
\hline
\end{tabular}

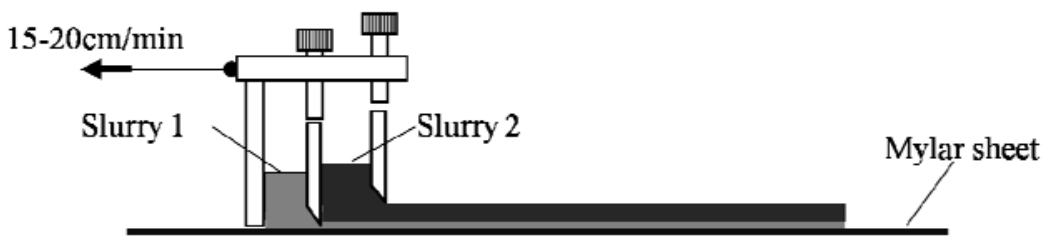

Fig. 1 Schematic illustration of phase inversion tape casting

The sintered YSZ-LSCrF membrane was modified at both sides [21, 22]. A porous YSZ-LSCrF layer was coated on the surface of the dense layer side by screen printing a YSZ-LSCrF slurry followed by firing at $1150{ }^{\circ} \mathrm{C}$ for $2 \mathrm{~h}$. The slurry used was prepared by dispersing the YSZ and LSCrF powder (with a volume ratio of 60:40) in terpineol and ethyl cellulose. Nano-particles of samarium doped ceria $\left(\mathrm{Sm}_{0.2} \mathrm{Ce}_{0.8} \mathrm{O}_{2-\delta}, \mathrm{SDC}\right)$ were deposited to the inner surfaces of the porous support by impregnation using an aqueous solution followed by firing 
at $800{ }^{\circ} \mathrm{C}$ for $2 \mathrm{~h}$. The solution was prepared from $\mathrm{Ce}\left(\mathrm{NO}_{3}\right)_{3}$ and $\mathrm{Sm}\left(\mathrm{NO}_{3}\right)_{3}(\mathrm{AR}$, Sinopharm Chemical Reagent Co.) in the stoichiometric molar ratio of SDC and with a total metal ion concentration of $0.5 \mathrm{M}$.

\subsection{Characterization}

The thermal decomposition of the green tape was analyzed using thermo-gravimetric analysis (TGA) (SDT Q600 V20.9 Build 20, TA Co. LTD) at a heating rate of $2{ }^{\circ} \mathrm{C} / \mathrm{min}$ in air. The morphology of the green tape and the microstructure of the sintered membrane were examined by scanning electron microscopy (SEM) (JSM-6390LA, JEOL, Japan). The porosity of the as-prepared membrane was measured by the Archimedes drainage method.

The oxygen permeability of the composite membrane was measured using the set-up shown in Fig. 2. A permeation cell was constructed comprising a membrane of effective area $6.8 \mathrm{~cm}^{2}$. The dense side of the membrane was exposed to an air stream at a feed rate of $100 \mathrm{ml} \cdot \mathrm{min}^{-1}$, and the porous support side to $\mathrm{CO}$ at a feed rate of $35 \mathrm{ml} \cdot \mathrm{min}^{-1}$. The effluents were analyzed with an online gas chromatography (GC) (GC9790 , Fuli, China), equipped with a thermal conductivity detector and two columns, one filled with 5A molecular sieves for oxygen and nitrogen detection and the other with TDX-01 for $\mathrm{CO}$ and $\mathrm{CO}_{2}$ detection at $800-900{ }^{\circ} \mathrm{C}$. The oxygen permeation flux was determined from the concentrations of oxygen and oxygen-containing species in the effluent and the flow rate at the outlet. 


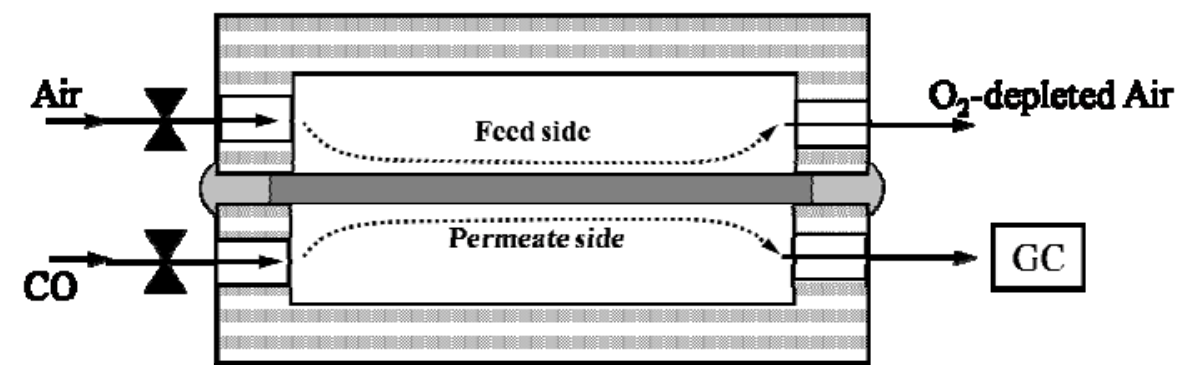

Fig. 2 Schematic diagram of the oxygen permeation measurement set-up

\section{Results}

Fig. 3 shows the cross-sectional SEM image of an as-prepared green tape. The green tape possessed a typical morphology and structure associated with the phase inversion solidification process. The finger-like top layer was derived from the slurry of YSZ-LSCrF and graphite, while the sponge-like bottom layer from the graphite-free slurry.

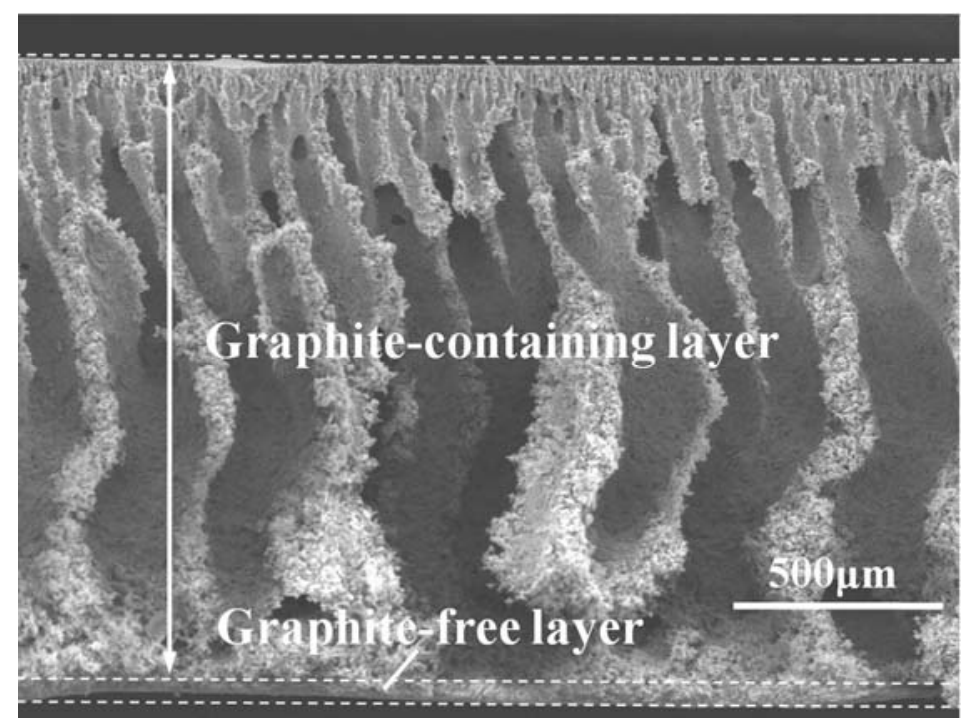

Fig. 3 SEM image of cross section of a green tape

Fig. 4 presents the thermo-gravimetric analysis of the green tape. A slight weight loss occurred from room temperature to $\sim 400{ }^{\circ} \mathrm{C}$ due to the vaporation of residual water and NMP. The weight loss accelerated above $\sim 400{ }^{\circ} \mathrm{C}$, and leveled off at temperatures above $\sim 800{ }^{\circ} \mathrm{C}$. A DTG peak appeared at $\sim 510{ }^{\circ} \mathrm{C}$, which was caused by the oxidation of the polymer constituents in the 
green tape. Another DTG peak appeared at $\sim 736{ }^{\circ} \mathrm{C}$, which was attributed to the oxidation of the graphite contained in the finger-like layer $[19,21]$.

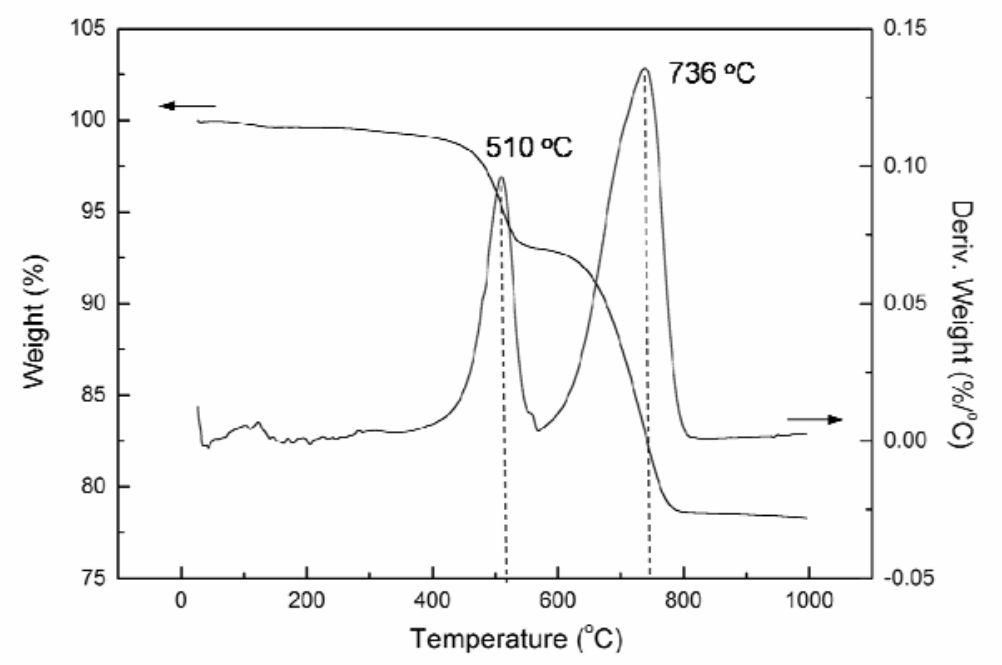

Fig. 4 TGA curves of the green tape

The green tape was sintered into a ceramic membrane after firing at $1450{ }^{\circ} \mathrm{C}$. The sintered membrane had an overall porosity of $\sim 50 \%$ as measured by the Archimedes drainage method. Fig. 5 shows the SEM images of a sintered membrane. The membrane consisted of a dense layer of thickness $\sim 30 \mu \mathrm{m}$ and a porous support of thickness $\sim 1 \mathrm{~mm}$. The dense layer had a fine-grained dense structure, which would be permeable to oxygen while imperious to nitrogen and other gaseous species. The support contained large finger-like pores and small pores in the walls. The finger-like large pores were formed in the phase inversion solidification step and survived the subsequent sintering step, while the small pores in the walls were arose from the removal of the graphite during the firing step. Note that the finger-like pores were straightly aligned along the membrane thickness direction, thus would not constitute a large resistance to the transport of gaseous species. These straight pores were fully opened up, making it easy to modify the inner 
surfaces of the support.

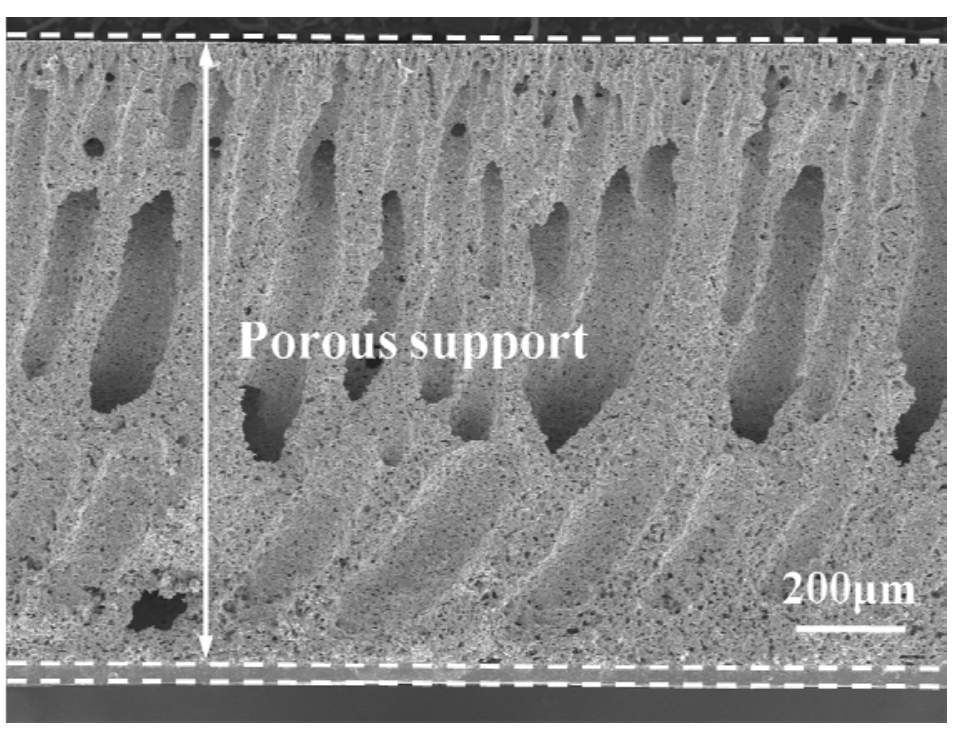

(a)

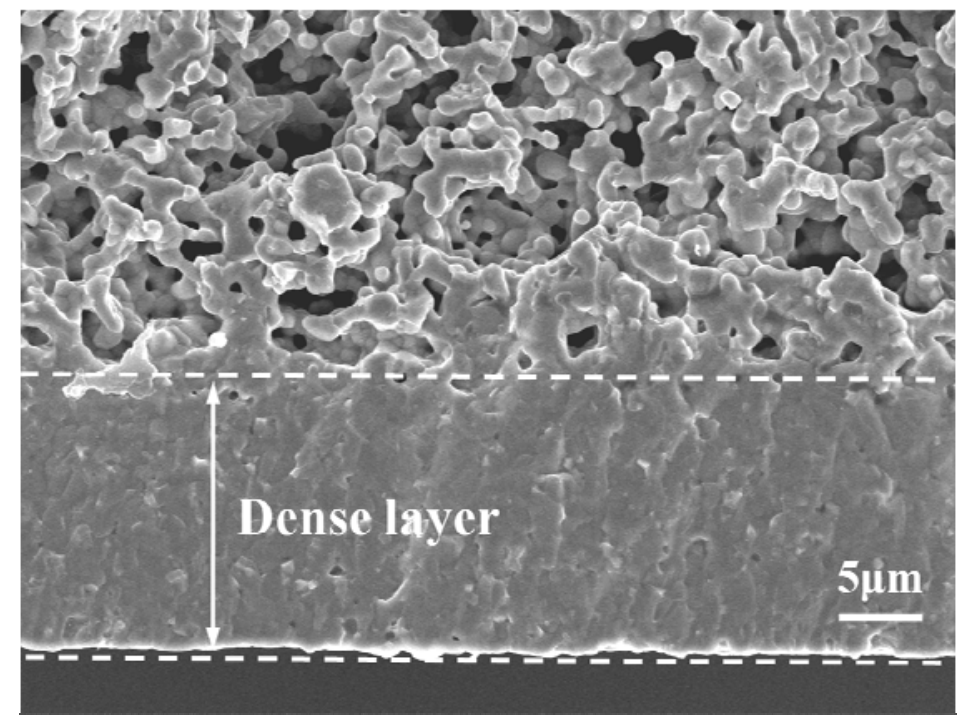

(b) 


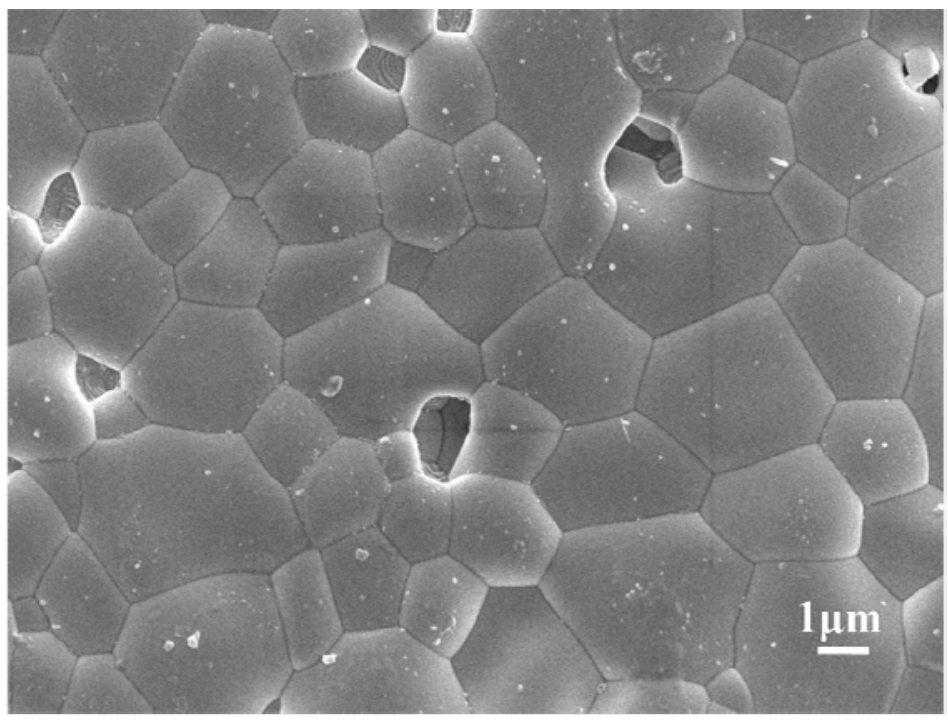

(c)

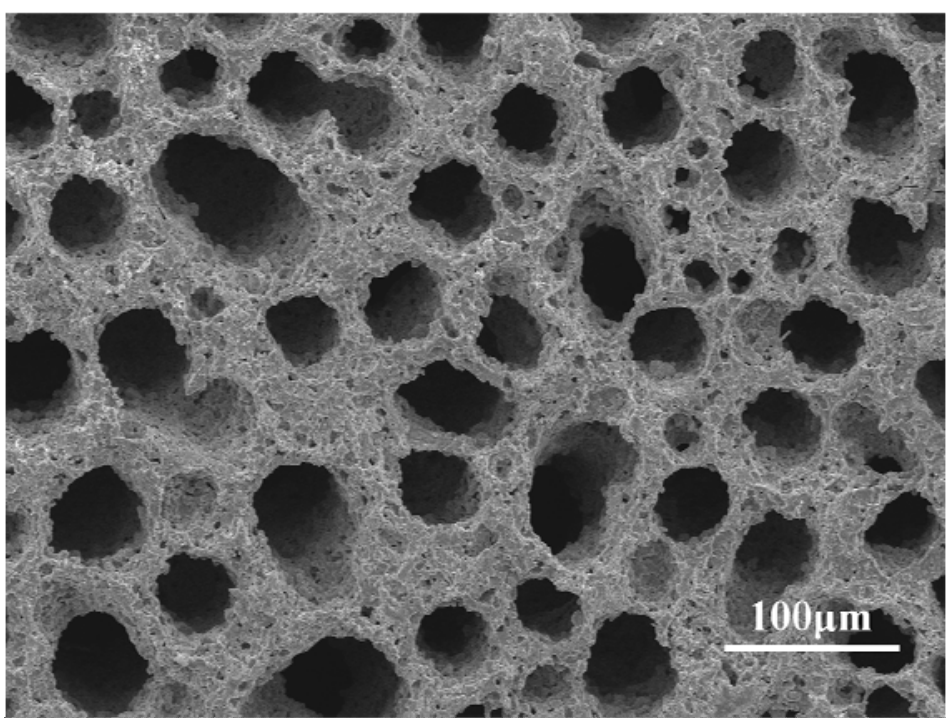

(d)

Fig. 5 SEM images of the sintered YSZ-LSCrF membrane: (a) overall cross-sectional view, (b) cross-sectional view of the dense layer, (c) surface of the dense layer, (d) cross section of the support perpendicular to the thickness direction.

A porous YSZ-LSCrF layer was coated on the surface of the dense layer side by screen-printing, and nano-particles of SDC were deposited on the inner surfaces of porous support by impregnation. As shown in Fig. 6a, the coated YSZ-LSCrF layer had a uniform porous 
structure with a thickness of $\sim 10 \mu \mathrm{m}$, and was well adhered to the dense layer. On the inner surface of the support (Fig. 6b), the uniformly distributed SDC nano-particles had an average diameter of $300-500 \mathrm{~nm}$.

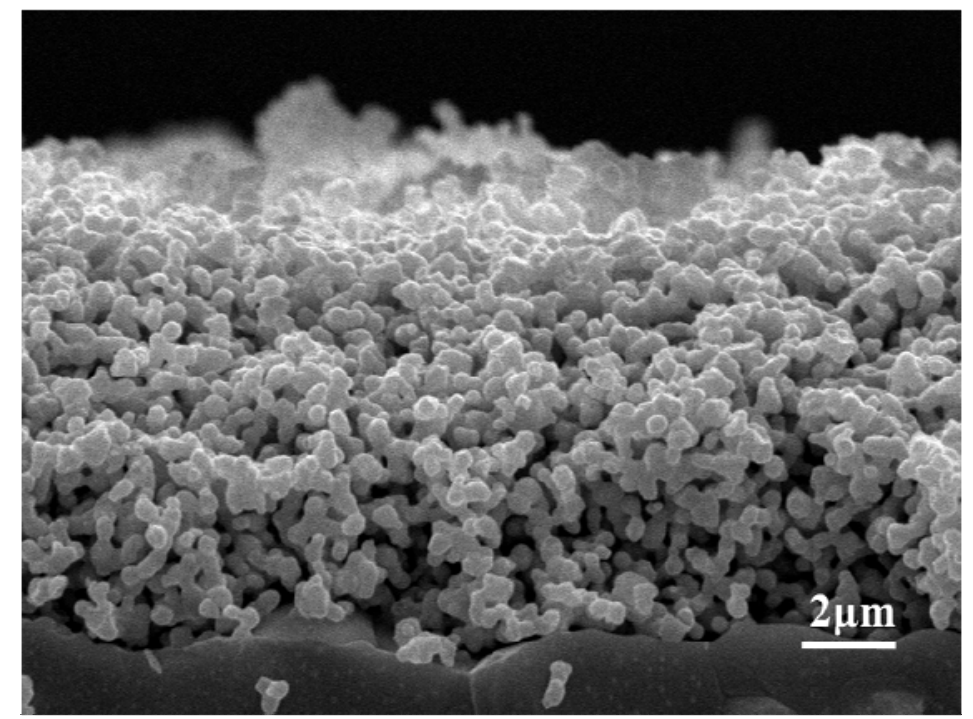

(a)

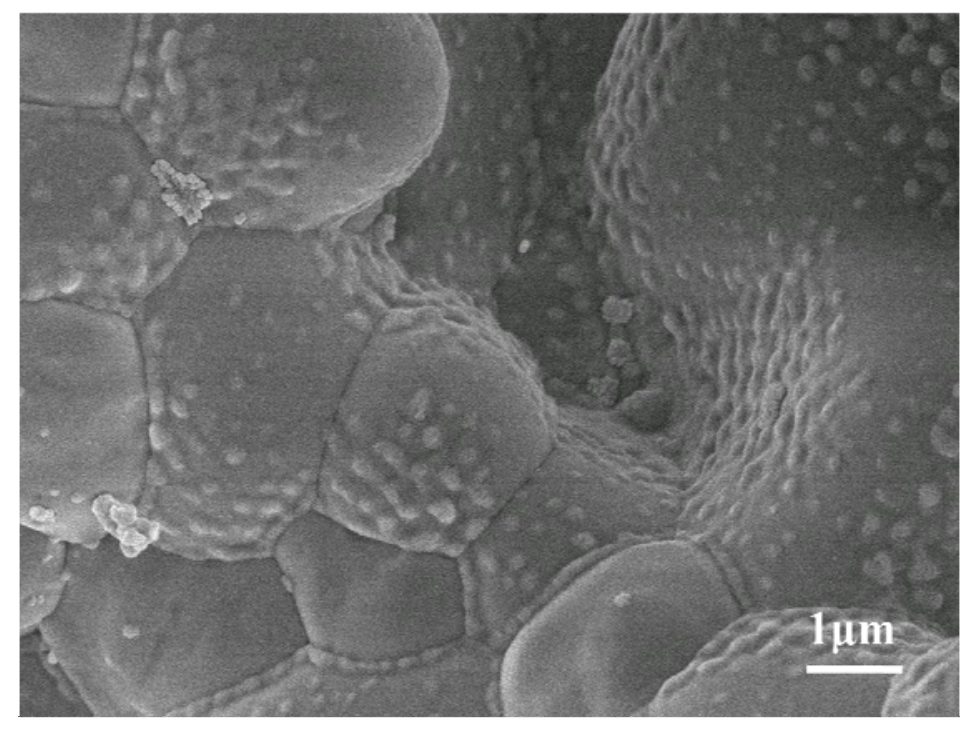

(b)

Fig. 6 SEM images of the modified YSZ-LSCrF membrane: (a) cross-sectional view of the coated layer, (b) inner surface of the support.

Fig. 7 shows the Arrhenius plots of oxygen permeation of the bare and modified YSZ-LSCrF 
membranes under air/CO gradient at $800-900{ }^{\circ} \mathrm{C}$. It can be seen that the as-prepared bare membrane exhibited an appreciable oxygen permeation flux at elevated temperatures. An oxygen permeation flux of $1.3 \mathrm{ml} \cdot \mathrm{cm}^{-2} \cdot \mathrm{min}^{-1}(\mathrm{STP})$ was obtained at $900{ }^{\circ} \mathrm{C}$. The oxygen permeation flux increased with temperature, and the associated activation energy was $89.2 \pm 3.9 \mathrm{~kJ} \cdot \mathrm{mol}^{-1}$. It can also be seen that the modified membrane exhibited a higher oxygen permeation flux compared with the bare membrane. An oxygen permeation flux of $2.4 \mathrm{ml} \cdot \mathrm{cm}^{-2} \cdot \mathrm{min}^{-1}$ (STP) was obtained at $900{ }^{\circ} \mathrm{C}$, which is almost twice of the value obtained from the bare membrane. The activation energy for the modified membrane was much smaller $\left(64.2 \pm 4.2 \mathrm{~kJ} \cdot \mathrm{mol}^{-1}\right)$ than that for the bare membrane, indicating that the surface oxygen exchange has been promoted by the surface modification.

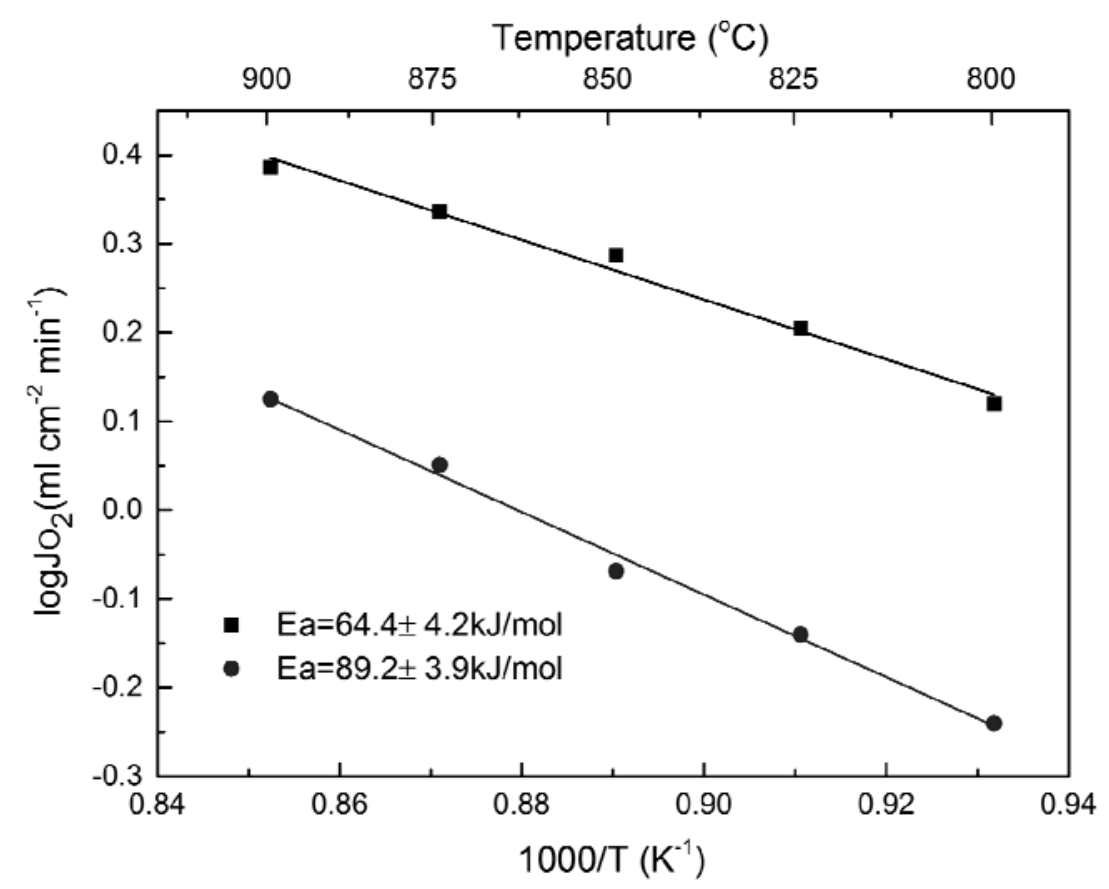

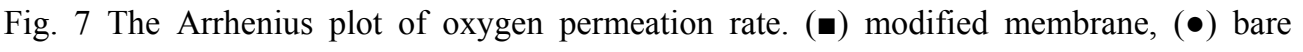
membrane. 


\section{Discussion}

It is clear that the oxygen permeation through the supported membranes involves the transport of oxide ions and electrons in the bulk of the dense layer, the transport of gaseous molecules in the support, and the oxygen exchange between the gas phase and the membrane surface. The structure features favored for each of these steps in oxygen permeation process could be obtained using the phase inversion tape casting method developed in the present study. Unlike the earlier variant of the phase inversion tape casting method which made use of a single slurry of ceramics $[19,20]$, the current one makes use of two different slurries, one containing fugitive pore former (graphite) for preparation of the support, and the other free of the pore former for preparation of the dense separation layer. The use of the two slurries enables better control of the membrane structure. In particular, the thickness of the dense separation layer of the supported membrane can be reduced significantly so as to speed up the bulk transport step and thus the overall oxygen permeation process. The thickness of the dense separation layer produced with the present method was as small as $\sim 30 \mu \mathrm{m}$, while it was much thicker $(\sim 150 \mu \mathrm{m})$ with the earlier method [19]. The current method also makes it possible to adjust the porosity of the support layer through the use of a ceramic slurry containing fugitive pore former. The finger-like pores in the as-prepared support of the membrane were fully opened up, allowing fast gas phase transport and thus beneficial for the overall oxygen permeation process. The opening up of the pores in the support also makes it easy to modify the inner pore surfaces of the membrane so as to promote the surface oxygen exchange and thus the overall oxygen permeation process.

This study shows that the as-prepared supported planar YSZ-LSCrF membrane exhibited a reasonably high oxygen permeation flux under the air/CO gradient at elevated temperatures. An 
oxygen permeation flux as large as $2.4 \mathrm{ml} \cdot \mathrm{cm}^{-2} \cdot \mathrm{min}^{-1}$ (STP) was observed at $900{ }^{\circ} \mathrm{C}$, which is comparable to the value reported for a hollow fiber membrane of the same membrane composition [12]. It has been reported that the YSZ-LSCrF composite membrane possesses desired stability under stringent operation conditions. Therefore, it is likely that the planar supported YSZ-LSCrF composite membrane developed in the present study can be used in chemical reactors integrating oxygen separation and chemical reactions such as POM.

\section{Conclusions}

A supported planar YSZ-LSCrF composite membrane has been prepared using a new variant of phase inversion tape casting method. The membrane consisted of a dense separation layer of reduced thickness $\sim 30 \mu \mathrm{m}$ and a mechanical support of thickness $\sim 1 \mathrm{~mm}$. The finger-like large pores in the support were fully opened up, allowing fast gas phase transport and further modification of the inner surfaces. The as-prepared supported planar membrane exhibited a reasonably high oxygen permeation flux with its dense layer side exposed to air and the porous support side to $\mathrm{CO}$ at elevated temperature. An oxygen permeation flux as large as 2.4 $\mathrm{ml} \cdot \mathrm{cm}^{-2} \cdot \mathrm{min}^{-1}$ (STP) was obtained at $900{ }^{\circ} \mathrm{C}$, which is comparable to the hollow fiber membrane of the same composition. Owing to its desired oxygen permeability and good stability, the as-prepared membrane is promising for chemical reactor applications such as POM. The preparation method developed in the present study can be applied to the preparation of other ceramic membranes.

\section{Acknowledgment}


This research was supported by National Science Foundation of China (Grant Nos. 21176230, 21271164).

\section{References}

[1] Y. Teraoka, H.M. Zhang, S. Furukawa, N. Yamazoe, Chem Lett (1985) (11) 1743.

[2] H.J.M. Bouwmeester, A.J. Burggraaf, Fundamentals of Inorganic Membrane Science and Technology (1996) 435(Chapter 10).

[3] P.N. Dyer, R.E. Richards, S.L. Russek, D.M. Taylor, Solid State Ionics 134 (2000) (1-2) 21.

[4] C.S. Chen, S.J. Feng, S. Ran, D.C. Zhu, W. Liu, H.J.M. Bouwmeester, Angew Chem Int Edit 42 (2003) (42) 5196.

[5] Y. Takahashi, A. Kawahara, T. Suzuki, M. Hirano, W. Shin, Solid State Ionics 181 (2010) (5-7) 300.

[6] B. Steele, Cr Acad Sci Ii C 1 (1998) (9) 533.

[7] H. Lu, Y. Cong, W.S. Yang, Solid State Ionics 177 (2006) (5-6) 595.

[8] C.H. Chen, H.J.M. Bouwmeester, R.H.E. vanDoorn, H. Kruidhof, A.J. Burggraaf, Solid State Ionics 98 (1997) (1-2) 7.

[9] S. Pei, M.S. Kleefisch, T.P. Kobylinski, J. Faber, C.A. Udovich, V. Zhangmccoy, B. Dabrowski, U. Balachandran, R.L. Mieville, R.B. Poeppel, Catal Lett 30 (1995) (1-4) 201.

[10] X.H. Gu, L. Yang, L. Tan, W.Q. Jin, L.X. Zhang, N.P. Xu, Ind Eng Chem Res 42 (2003) (4) 795.

[11] W. He, H. Huang, M. Chen, J.F. Gao, C.S. Chen, Solid State Ionics 260 (2014) 86.

[12] J.J. Liu, T. Liu, W.D. Wang, J.F. Gao, C.S. Chen, J Membrane Sci 389 (2012) 435.

[13] T. Liu, C. Ren, S.M. Fang, Y. Wang, F.L. Chen, Acs Appl Mater Inter 6 (2014) (21) 18853. 
[14] S. Baumann, J.M. Serra, M.P. Lobera, S. Escolastico, F. Schulze-Kuppers, W.A. Meulenberg, J Membrane Sci 377 (2011) (1-2) 198.

[15] W.Q. Jin, S.G. Li, P. Huang, N.P. Xu, J. Shi, J Membrane Sci 185 (2001) (2) 237.

[16] V. Kozhukharov, M. Machkova, N. Brashkova, J Sol-Gel Sci Techn 26 (2003) (1-3) 753.

[17] G.Y. Meng, H.Z. Song, H.B. Wang, C.R. Xia, D.K. Peng, Thin Solid Films 409 (2002) (1) 105.

[18] O. Buchler, J.M. Serra, W.A. Meulenberg, D. Sebold, H.P. Buchkremer, Solid State Ionics 178 (2007) (1-2) 91.

[19] W. He, H. Huang, J.F. Gao, L. Winnubst, C.S. Chen, J Membrane Sci 452 (2014) 294.

[20] C.L. Ren, H. Fang, J.Q. Gu, L. Winnubst, C.S. Chen, J Eur Ceram Soc 35 (2015) (2) 723.

[21] R.H. Yuan, W. He, Y. Zhang, J.H. Gao, C.S. Chen, J Membrane Sci 499 (2016) 335.

[22] T. Liu, Y. Wang, R.H. Yuan, J.F. Gao, C.S. Chen, H.J.M. Bouwineester, Acs Appl Mater Inter 5 (2013) (19) 9454. 
Tables

Table 1 Composition of slurries for phase-inversion tape casting (wt \%) 
Figure captions:

Fig. 1 Schematic illustration of phase inversion tape casting

Fig. 2 Schematic diagram of the oxygen permeation measurement set-up

Fig. 3 SEM image of cross section of a green tape

Fig. 4 TGA curves of the green tape

Fig. 5 SEM images of the sintered YSZ-LSCrF membrane: (a) overall cross-sectional view, (b) cross-sectional view of the dense layer, (c) surface of the dense layer, (d) cross section of the support perpendicular to the thickness direction.

Fig. 6 SEM images of the modified YSZ-LSCrF membrane: (a) cross-sectional view of the coated layer, (b) inner surface of the support.

Fig. 7 The Arrhenius plot of oxygen permeation rate. ( $(\mathbf{)})$ modified membrane, $(\bullet)$ bare membrane. 